FY 2005

\title{
RADIAL-GAP PERMANENT MAGNET MOTOR AND DRIVE RESEARCH FY 2004
}

Prepared by:

Oak Ridge National Laboratory

Laura D. Marlino, Program Manager

Submitted to:

Energy Efficiency and Renewable Energy

FreedomCAR and Vehicle Technologies

Vehicle Systems Team

Susan A. Rogers, Technology Development Manager

February 2005 
NATIONAL LABORATORY

MANAGED BY UT-BATTELLE

FOR THE DEPARTMENT OF ENERGY

\section{Engineering Science \& Technology Division}

\section{RADIAL-GAP PERMANENT MAGNET \\ MOTOR AND DRIVE RESEARCH \\ FY 2004}

J. W. McKeever

J. M. Bailey

G. J. Su

J. S. Hsu

C. W. Ayers

L. E. Seiber

Oak Ridge National Laboratory

J. S. Lawler

The University of Tennessee-Knoxville

Publication Date: February 2005

Prepared by the

OAK RIDGE NATIONAL LABORATORY

Oak Ridge, Tennessee 37831

managed by

UT-BATTELLE, LLC

for the

U.S. DEPARTMENT OF ENERGY

Under Contract DE-AC05-00OR22725 
This report was prepared as an account of work sponsored by an agency of the United States Government. Neither the United States Government nor any agency thereof, nor any of their employees, makes any warranty, express or implied, or assumes any legal liability or responsibility for the accuracy, completeness, or usefulness of any information, apparatus, product, or process disclosed, or represents that its use would not infringe privately owned rights. Reference herein to any specific commercial product, process, or service by trade name, trademark, manufacturer, or otherwise, does not necessarily constitute or imply its endorsement, recommendation, or favoring by the United States Government or any agency thereof. The views and opinions of authors expressed herein do not necessarily state or reflect those of the United States Government or any agency thereof. 


\section{TABLE OF CONTENTS}

Page

LIST OF FIGURES

iii

ACRONYMS

iv

1. INTRODUCTION

1.1 SUMMARY OF ACTIVITIES AND POSSIBLE FUTURE WORK

1

1.2 BACKGROUND.

2. THE DMIC INVERTER.

4

2.1 TESTING THE DMIC INVERTER ……...................................................................

2.2 DMIC MINIMIZES CURRENT USED BY MOTOR .................................................... 8

2.3 ONSET OF YIELD DETERMINES MAXIMUM OPERATION SPEED $\ldots \ldots \ldots \ldots \ldots \ldots \ldots \ldots . . . . . . . . . . .10$

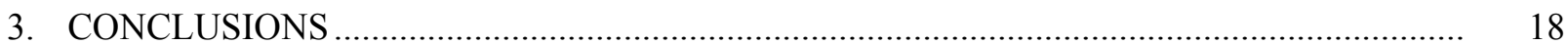

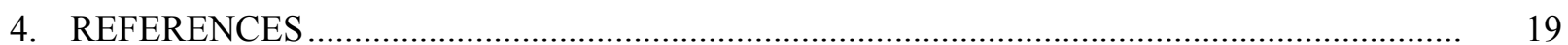

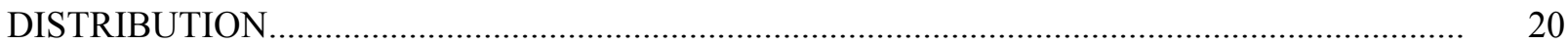




\section{LIST OF FIGURES AND TABLES}

Figure

Page

$1 \quad$ Extent of motor derating caused by demagnetization.................................................. 5

2 Demagnetization reflected by changes in back-emf during testing of the DMIC ............. 6

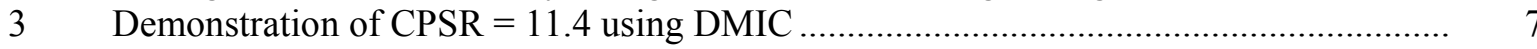

$4 \quad$ Demonstrating of CPSR $=11.2$ using CPA control ................................................. 7

$5 \quad$ Fan load penalty and change in no-load spin losses related to demagnetization

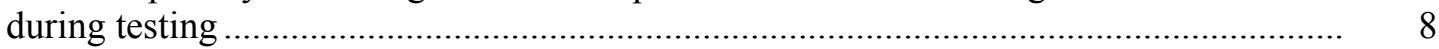

$6 \quad$ Constant power operation of a PMSM comparing CPA control with DMIC .................... 10

$7 \quad$ Evolving IPM rotor configurations (THS left, THSII right) …........................................ 12

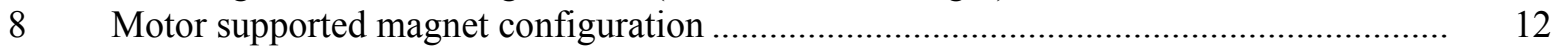

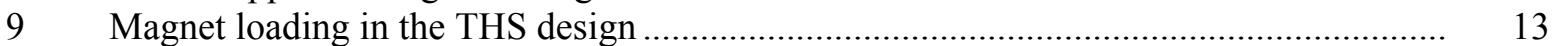

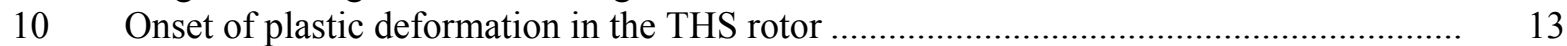

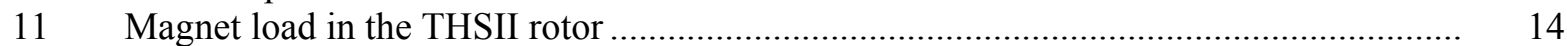

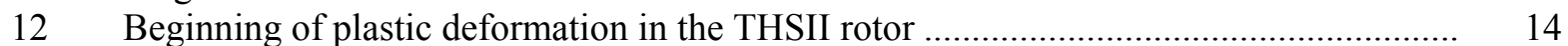

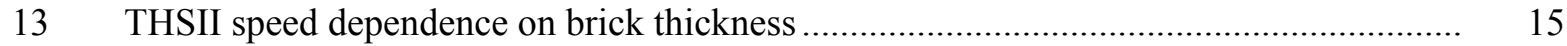

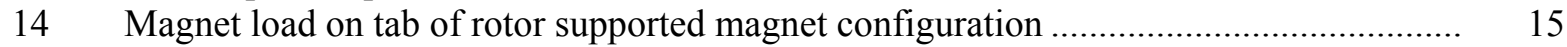

15 Onset of plastic compression in rotor that supports its own magnets.............................. 16

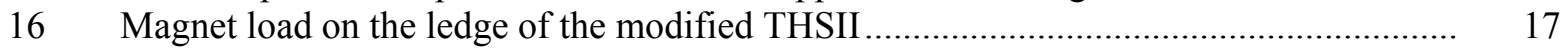

17 Onset of plastic deformation in the modified THSII ................................................... 17 


\section{ACRONYMS}

$\begin{array}{ll}\text { BDCM } & \text { brushless dc motor } \\ \text { CPA } & \text { conventional phase advance } \\ \text { CPSR } & \text { constant power speed ratio } \\ \text { DMIC } & \text { dual mode inverter control } \\ \text { DSP } & \text { digital signal processor } \\ \text { emf } & \text { electromotive force (measured in volts) } \\ \text { FEA } & \text { finite-element analyses } \\ \text { HEV } & \text { hybrid electric vehicle } \\ \text { HSU } & \text { high-strength undiffused } \\ \text { HSUB } & \text { high-strength undiffused brushless } \\ \text { IPM } & \text { interior permanent magnet } \\ \text { ORNL } & \text { Oak Ridge National Laboratory } \\ \text { PEEMRC } & \text { Power Electronics and Electric Machinery Research Center } \\ \text { PM } & \text { permanent magnet } \\ \text { PMSM } & \text { permanent magnet synchronous motor } \\ \text { SCR } & \text { silicon-controlled rectifier } \\ \text { THS } & \text { Toyota Hybrid System (2003) } \\ \text { THSII } & \text { Toyota Hybrid System (new generation-2004) } \\ \text { VSI } & \text { voltage source inverter }\end{array}$




\section{INTRODUCTION}

The objective of this task was to study permanent magnet (PM) radial-gap traction drive systems that could meet the U.S. Department of Energy FreedomCAR Program's 2010 goals to expose weaknesses or identify strengths. Initially, the approach was to compare attributes such as physical deformations during operation, performance (torque, power, efficiency versus speed), material requirements (strength), material costs, manufacturability, weight, power density, specific power, reliability, and drivability for specific motors. Three motors selected were the commercially available $60-\mathrm{kW}$ radial-gap surfacemounted PM motor manufactured by UQM Technologies, Inc.; a hypothetical PM motor with rotorsupported magnets similar to the Honda MCF-21; and Delphi's automotive electric machine drive motor, whose rotor is a ferromagnetic cylinder, held at one end by a shaft that supports the magnets on its inner surface.

Potential problems have appeared related to PM motors, such as (1) high no-load spin losses and high operational power losses, probably from eddy current losses in the rotor; (2) the undemonstrated dual mode inverter control (DMIC) for driving a brushless de motor (BDCM) (UQM and Delphi motors); (3) uncertainty about the potential for reducing current with DMIC; and (4) uncertainty about the relation between material requirements and maximum rotor speed. Therefore, the approach was changed to study in detail three of the comparison attributes: drivability, performance, and material requirements.

Drivability and related problems were examined by demonstrating that DMIC may be used to drive an 18-pole 30-kW PM motor to $6000 \mathrm{rpm}$, where the maximum electrical frequency is $900 \mathrm{~Hz}$. An available axial-gap test motor with 18 poles was used because its control is identical to that of a radial gap PM motor.

Performance was analytically examined, which led to a derivation showing that DMIC controls a PM motor so that the motor uses minimum current to produce any power regardless of speed for relative speeds, $\mathrm{n}=\omega / \omega_{\text {base }} \geq 2$. Performance was also examined with efficiency measurements during the $30-\mathrm{kW}$ PM motor test.

Material requirements were examined with finite-element analyses (FEA) to determine the speed and location where yield starts and the corresponding deformations and stresses.

\subsection{SUMMARY OF ACTIVITIES AND POSSIBLE FUTURE WORK}

In the process of demonstrating the DMIC inverter, an 18-pole axial-gap design concept, which uses minimum rotor and magnet material, was driven by the dynamometer motor to $6600 \mathrm{rpm}$, which is $10 \%$ above maximum operating speed, to confirm the design's mechanical soundness. The design concept comprises magnets butted and skewed by one rotor tooth and secured by radial interference in an annular region between a titanium ring and an aluminum hub, relying on the magnets' compressive strength as

part of the structure. An additional feature, confirmed by the 6600 -rpm operation, was the shaft-mounted axial vane pump used to cool the rotor and stator.

A DMIC successfully drove the 18-pole PM motor to $6000 \mathrm{rpm}$, which corresponds to an electrical frequency of $900 \mathrm{~Hz}$. This not only demonstrated the DMIC's ability to drive the motor but also demonstrated that its converter-grade silicon-controlled rectifiers (SCRs), which can normally withstand higher voltages and are less expensive than inverter-grade SCRs because they commute off naturally, could operate at this high frequency. During the test, a record constant power speed range (CPSR) of 11.4 was attained with DMIC. DMIC operation was compared with conventional phase advance (CPA) operation for the motor by bypassing the SCRs, leading to a value of 11.2. The excellent performance of 
CPA is probably due to the high inductance of the motor, but a more complete explanation should be sought in FY 2005.

During the test, severe demagnetization occurred that was sufficient to reduce the $30-\mathrm{kW}$ power rating to $12 \mathrm{~kW}$, confirming a problem that has appeared in the commercial sector. Demagnetization is likely to result from a significant rapid heat rise from eddy currents induced in the rotor that were undetected by temperature sensors on the stator. A methodology is available [1] for calculating the losses generated by eddy currents in the rotor, a region whose losses we have previously ignored. This methodology may be applied to estimate the no-load spin loss from eddy currents generated by the magnets passing the slot opening and the operating eddy current losses generated by harmonics; to compare motor operation using trapezoidal and sinusoidal back-electromotive forces (emfs); to compare measured results with test results; and to estimate adiabatic temperature rise in the rotor. A rapid adiabatic temperature rise would confirm eddy currents in the rotor could have caused demagnetization. Evaluation and comparison of the data with the equations should be conducted in FY 2005.

A paper in IEEE PE Letters [2] relegated the DMIC to an equivalent fixed inductor in each phase using a fundamental frequency phasor analysis of PM synchronous motors (PMSMs). Oak Ridge National Laboratory (ORNL) has extended the analysis to derive an equation for the inductive reactance that will minimize the current and still allow a fixed supply voltage to deliver rated power. This analysis has significant applications in determining the life-cycle cost benefit, provided the lifetime duty cycle for an application is known. In FY 2005, ORNL will prepare a paper to show how the equation for the inductive reactance of the DMIC is a variable whose control defines the minimum current needed to deliver any desired power at any relative speed over 2 , and that motors with larger inductances can derive significant benefit from DMIC, depending on their speed.

Use of FEA to evaluate the operating speed of radial gap PM motors was affirmed by comparing values with the operating speed of the Toyota THS and THSII design. FEA was then applied to determine the operating speeds of a rotor that supported its magnets to eliminate external support, and of an earlier version of an axial flux weakened/strengthened concept, which is supported by two peripheral bridges and two radial posts. This method should be used in FY 2005 to study new rotor concepts. For example, it could be used to identify an optimum magnet fraction for surface-mounted radial gap rotors that support their magnets, recognizing that the operating speed and reluctance component of torque will increase and the magnet cost will decrease as the embedded magnet fraction decreases.

\subsection{BACKGROUND}

Although induction motors have been considered the baseline for American hybrid electric vehicle (HEV) traction drives, most of the new marketable HEVs being sold by foreign sources such as Toyota and Honda are powered by PM motors. It has been difficult for U.S. suppliers to design and build a radial gap PM motor that meets FreedomCAR's 2010 goals. The goal of this research was to examine the source of some of these difficulties and see if solutions could be found. The approach initially proposed was to examine and compare the parameters of a commercially available surface-mounted radial gap PM motor sold by UQM, a PM motor with an external rotor whose surface-mounted magnets were secured to the inner surface, being developed and tested for possible commercial use by Delphi, and a PM motor like one being proposed by Honda, which has surface-mounted magnets held in place by Si steel hooks to form an alternating magnet-Si steel surface facing the gap. This approach had to be modified because much of the information needed for the comparison was proprietary to the vendors.

As we examined how best to continue this research, a number of problems and uncertainties arose that guided our revised approach. During discussions with the vendors and program reviews, we learned that they had encountered large heat losses during testing, which they ascribed to eddy currents induced in the 
rotor. We are concerned that this is a problem that must be faced by all PM motors. There are drive systems that employ vector control to drive PMSMs. However, an inverter capable of employing DMIC to drive BDCMs, although available, had not been tested specially for motors with large numbers of poles, which would require the SCRs to switch at frequencies near $12 \mathrm{kHz}$. Will the SCRs in the DMIC switch at these high frequencies, induced by the large pole count? Confusion surfaced about operation of the DMIC in an article in IEEE PE Letters [2], which concluded that DMIC is the same as a fixed inductance in each of the three phases of a PM motor and that a winding strategy that leads to large inductance cannot benefit from DMIC. How should the SCRs in the DMIC be truly characterized as an inductive reactance in each of the phases, and does this clarify their role in the controller? Finally, there were questions about how material properties related to the high speeds under which commercial rotors were being operated. Do the small bridges support operation at high speeds for ordinary materials? What can be learned from existing models that may be applied to future models?

The revised approach has been to study certain specific parameters of radial gap PM motors, namely drivability, performance, and material requirements. Drivability and performance were studied by testing the DMIC inverter by driving an 18-pole 30-kW PM motor to $6000 \mathrm{rpm}$, where the maximum electrical frequency is $900 \mathrm{~Hz}$. (An axial gap test motor with 18 poles was used because its control is identical to that of a radial gap PM motor.) Performance was also examined through analysis, which led to a derivation showing that DMIC produces any developed power with the minimum current necessary regardless of speed for relative speeds, $n=\omega / \omega_{\text {base }} \geq 2$. Material requirements were examined with FEA to determine the speed and location where yield starts and the corresponding deformations and stresses. 


\section{THE DMIC INVERTER}

\subsection{TESTING THE DMIC INVERTER}

The air-cooled 18-pole axial gap PM motor was driven to $6600 \mathrm{rpm}$ by the dynamometer motor and operated for 30 minutes to confirm its mechanical stability. The operation at $10 \%$ over speed supported the integrity of the motor design, which included two significant design features. The first design feature was an annulus comprising 18 butted magnets skewed one slot to reduce cogging torque and held by interference between a titanium ring and an aluminum hub. The interference was sufficient to accommodate differential radial growth as the speed increased and differential radial thermal expansion as the components heated. The second design feature was a bladed cooling fan that moved outside air past the stator and rotor.

The DMIC inverter used to drive the 18-pole PM motor at $6000 \mathrm{rpm}$ was configured for testing at a base speed of $1500 \mathrm{rpm}$ to a CPSR of 4 in the first testing, and at a base speed of $500 \mathrm{rpm}$ to a CPSR of 12 in the second testing. Filters were added to the gate circuit to reduce the noise to a level that allowed the motor to be driven.

The initial setup test goal was to apply maximum load torque, $191 \mathrm{~N}-\mathrm{m}$, at $1000 \mathrm{rpm}$, which is below base speed. With the dc supply voltage at $260 \mathrm{~V}$, considerably higher than the $209 \mathrm{~V}$ estimated, $181 \mathrm{~N}-\mathrm{m}$ was applied to the load before the inverter shut off. No current measurements were taken, but the probability is that the current was about $166 \mathrm{~A}_{\mathrm{rms}}\left(181 \mathrm{~N}-\mathrm{m} / 191 \mathrm{~N}-\mathrm{m} \times 175 \mathrm{I}_{\text {rated }}\right)$. The highest stator thermocouple reading was $180^{\circ} \mathrm{F}$.

On the next attempt to apply $191 \mathrm{~N}-\mathrm{m}$ load torque, the inverter shut off at $140 \mathrm{~N}-\mathrm{m}$. The Hall probe signals, which record the magnet field intensity in the gap, had changed significantly, indicating that the magnets had been demagnetized. This was confirmed by comparing the back-emf waveform at $1500 \mathrm{rpm}$ with a reference waveform taken prior to testing. The two humps, which were initially level, had become lopsided, which indicates non-uniform demagnetization; and the peak-to-peak voltage was reduced by $10 \%$.

To investigate the extent of demagnetization, the motor was operated at $800 \mathrm{rpm}$, which is below base speed, where it is more difficult for the fan to cool the motor. Torque was varied from 20 to $120 \mathrm{~N}-\mathrm{m}$ in steps of $20 \mathrm{~N}$-m while measuring the phase current. During testing at $155 \mathrm{~A}_{\mathrm{rms}}$, the temperature rose to $234^{\circ} \mathrm{F}$, at which temperature the test was terminated. The rate of rise indicated that the stabilization temperature was above $312^{\circ} \mathrm{F}$, which is above the recommended $302^{\circ} \mathrm{F}$ maximum operating temperature

for the magnet. Extrapolation of the curve in Fig. 1 shows that demagnetization has reduced the motor from 191 to $130 \mathrm{~N}-\mathrm{m}$ at rated current. Since our 800-rpm test at $155 \mathrm{~A}_{\text {rms }}$ would have exceeded the permissible temperature, we certainly should not operate above that value. Our testing will not exceed $120 \mathrm{~A}_{\mathrm{rms}}$ to limit stator temperature rate increase. 


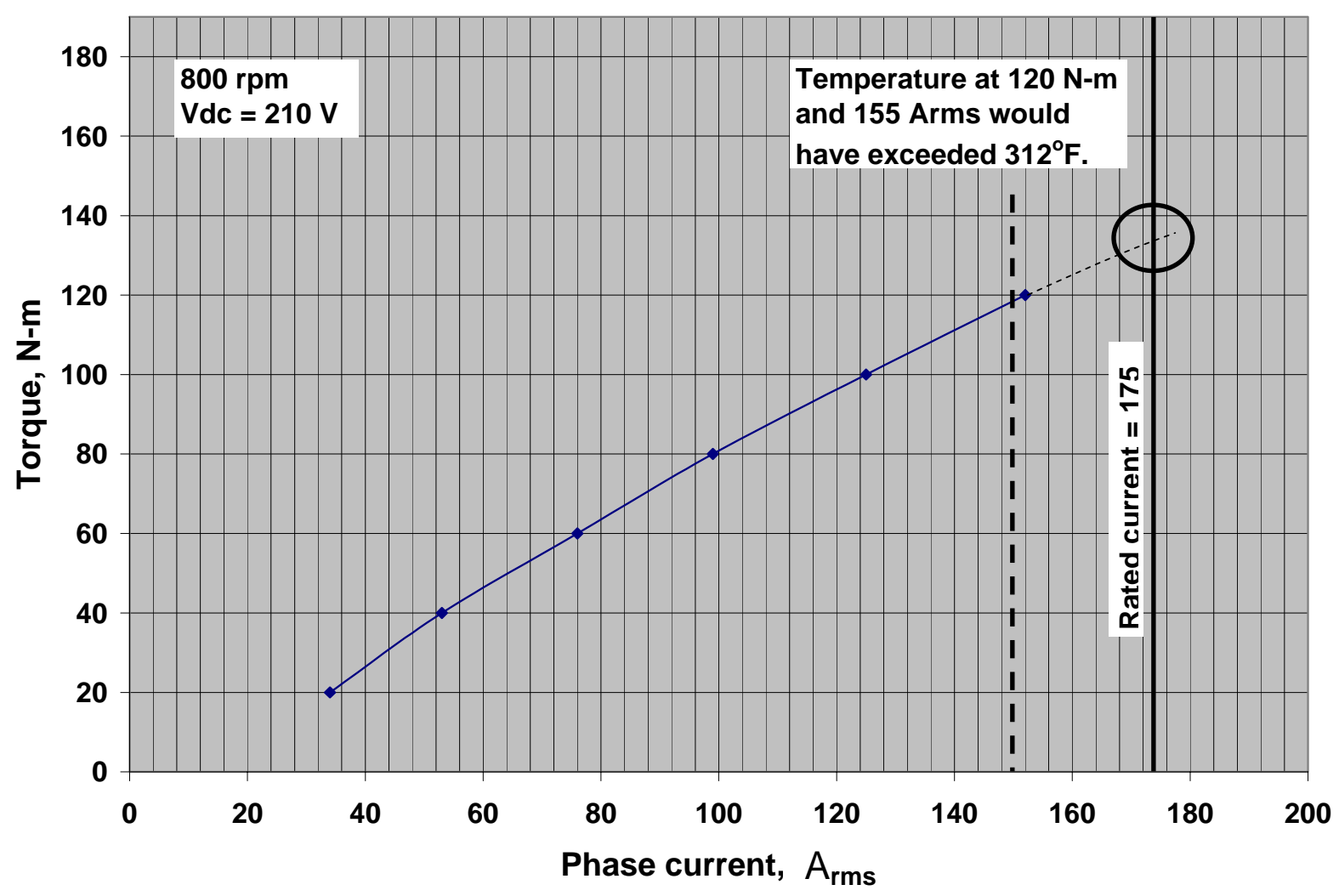

Fig. 1. Extent of motor derating caused by demagnetization.

During this test only the stator temperature was monitored. There was no sensor on the rotor. The stator temperature never rose to an alarming value. We infer, therefore, that the demagnetization resulted from rapid temperature rise in the rotor generated by harmonics, which are plentiful because the back-emf waveform is trapezoidal. During FY 2005 we plan to characterize the temperature rise of the rotor caused by the harmonics. Temperature rises of this type have been experienced by UQM on a PM radial gap motor, which had magnets mounted on its outer surface, and by Delphi on a PM radial gap motor, which had an external rotor with magnets mounted on its inner surface. UQM's solution was to use sinusoidal back-emfs to eliminate most of the harmonics. Delphi's solution was to segment the magnets and back iron. Segmentation of the axial gap test motor will be very difficult; however, strategic placement of electrical insulators at the interfaces between the Ti ring, the Al hub, and the magnets might help. First the order of magnitude of the problem must be estimated.

Demagnetization was also indicated by open-circuit back-emf measurements. Figure 2 shows the trend of the line-to-line, peak-to-peak back-emf measurements sampled during the course of the testing. The curves indicate a 58\% reduction in back-emf and imply that demagnetization continued during the entire test, which included DMIC operation at CPSR $=4$, DMIC operation at CPSR $=11.3$, and CPA operation at $\mathrm{CPSR}=11.2$. 


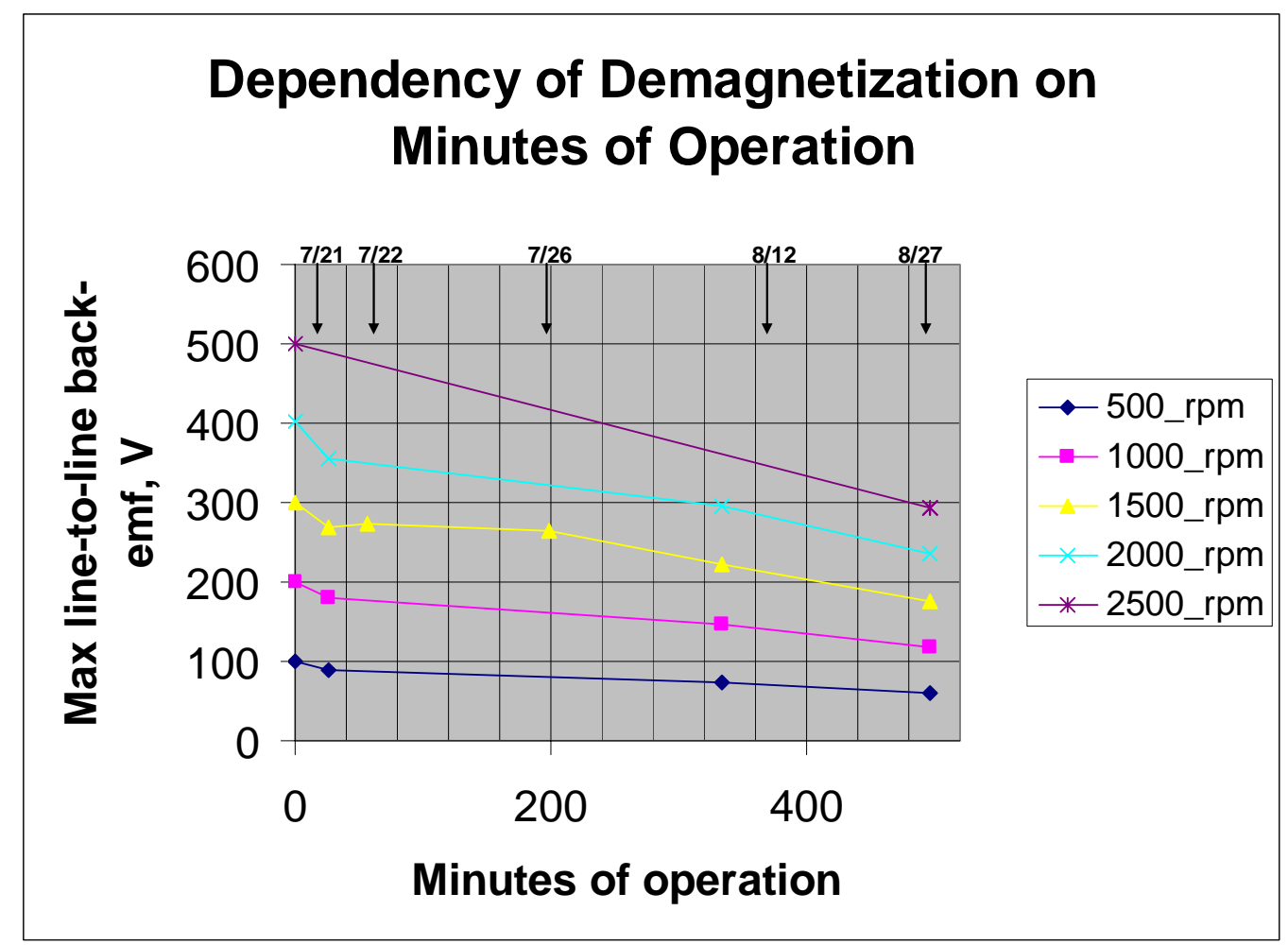

Fig. 2. Demagnetization reflected by changes in back-emf during testing of the DMIC.

In the first test sequence, the DMIC inverter drove the derated PM motor to deliver $12 \mathrm{~kW}$ from a base speed of $1500 \mathrm{rpm}$ to $6000 \mathrm{rpm}$, demonstrating a CPSR of 4. This successful drive-up proved that the SCRs, which are converter-grade devices, can switch at the electrical frequency of $900 \mathrm{~Hz}$. A convertergrade SCR is cheaper than inverter-grade SCRs and is rated to withstand higher voltages. This reduces the cost that these six devices add to the inverter.

The next test sequence attempted to demonstrate a record CPSR of 12 by delivering $5-\mathrm{kW}$ power from a base speed of $500 \mathrm{rpm}$ to $6000 \mathrm{rpm}$. The rated power at base speed was determined by reducing the supply voltage while delivering $80 \mathrm{~N}-\mathrm{m}$ at $500 \mathrm{rpm}$ until the speed began to drop. This voltage was then used through the rest of the test. Figure 3 shows how the power delivery initially rises above rated power at relatively constant current and then falls to define the CPSR at the speed where it crosses the rated power line. The value demonstrated in this test was 11.4 , which is a record and is very close to our target of 12 .

In question was the ability of CPA to drive this motor at a high CPSR. To investigate this mode of operation, the SCRs in the DMIC inverter were bypassed to enable CPA control. Because of the speed limitations of the earlier-technology digital signal processor (DSP), the motor could not be operated stably above $5200 \mathrm{rpm}$; but at that speed, the power was still above rated power. As shown in Fig. 4, an extrapolation of the last two data points estimates a CPSR of 11.2, which is also a record. 


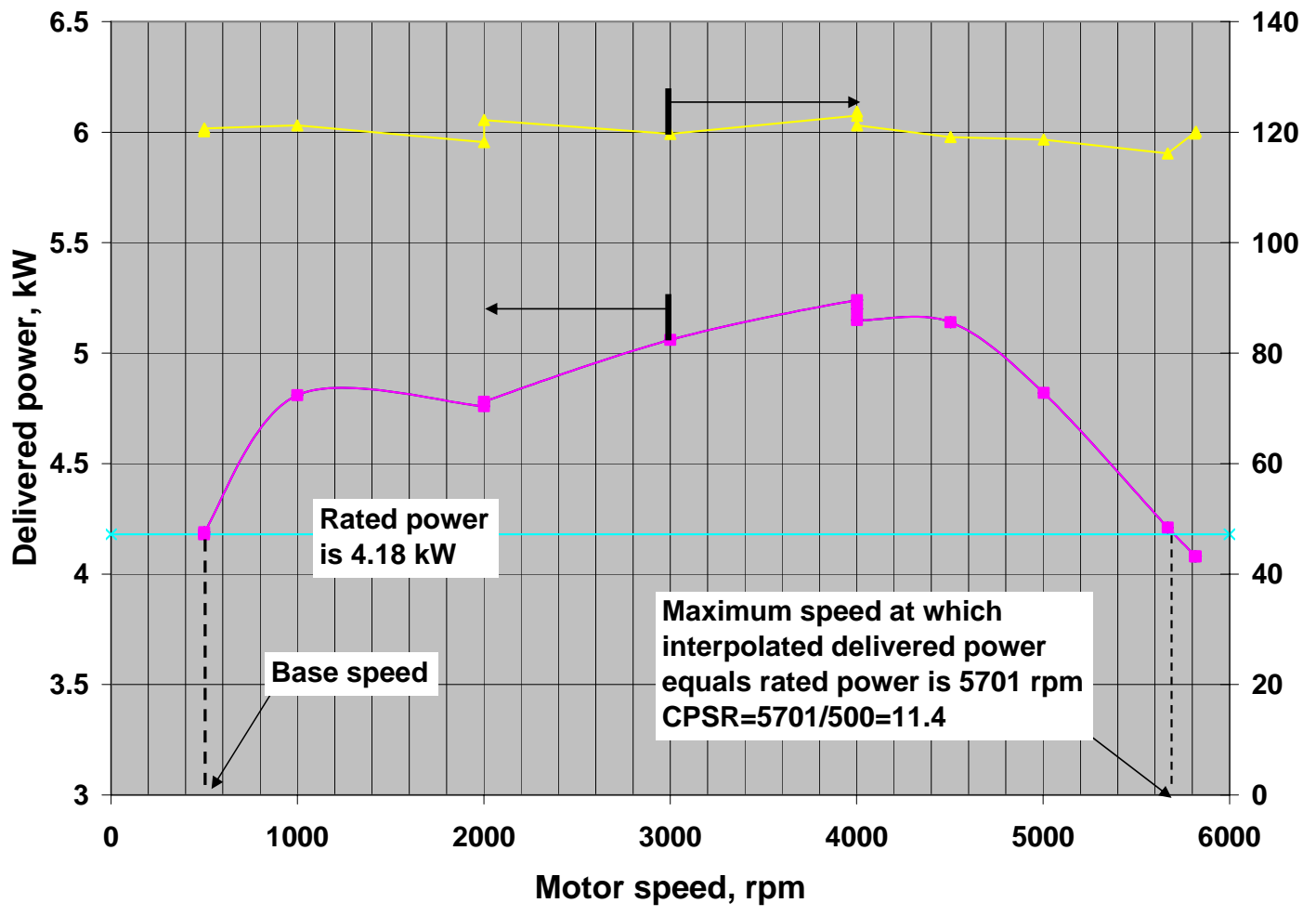

Fig. 3. Demonstration of CPSR $=11.4$ using DMIC.

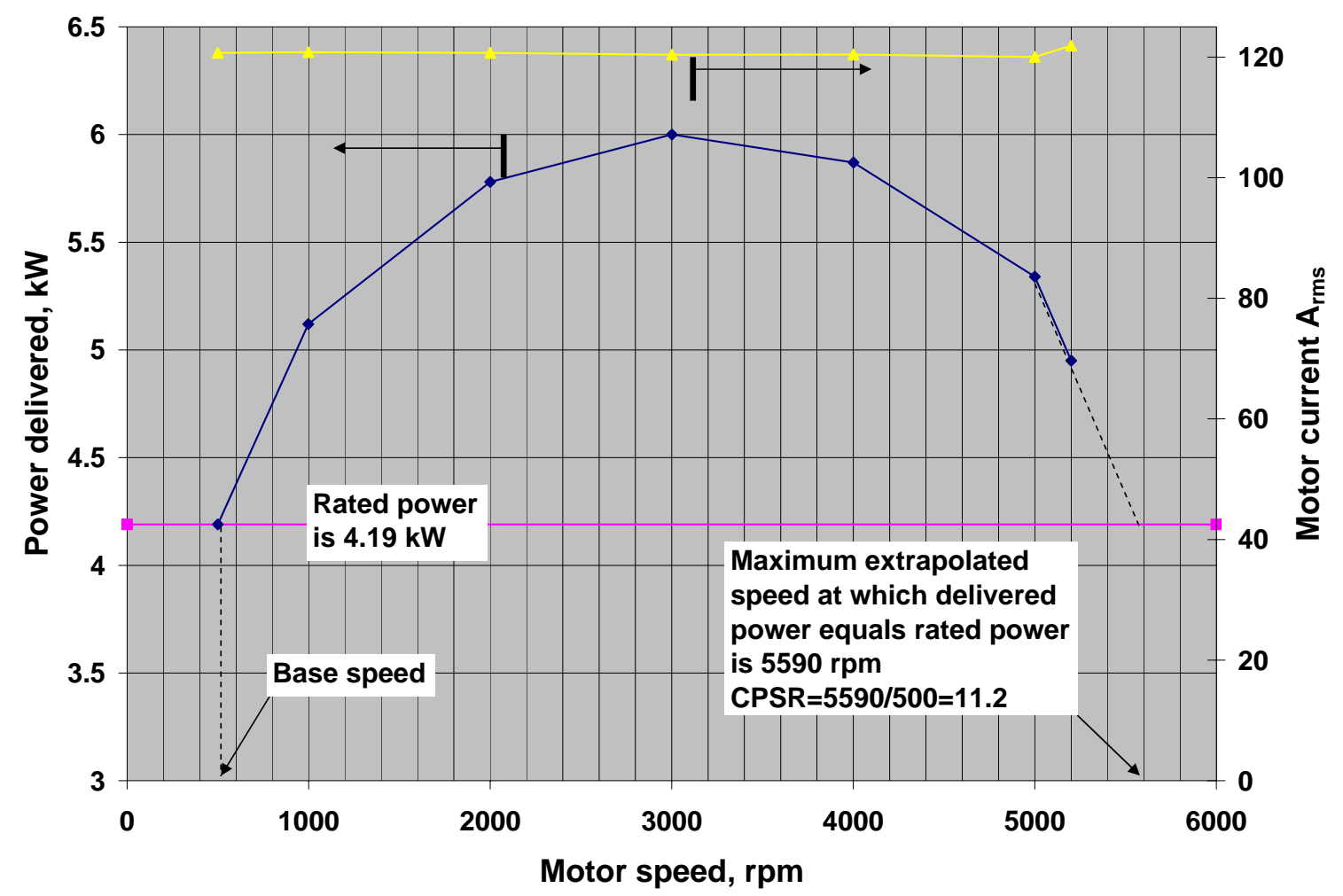

Fig. 4. Demonstration of CPSR $=11.2$ using CPA control. 
No-load spin losses measured at various stages during testing highlighted two phenomena, as shown in Fig. 5. First was the reduction in no-load spin losses associated with continuing demagnetization. Second was the huge amount of power that was consumed by the axial-vane air pump that cooled the motor. The fan consumed over $2 \mathrm{~kW}$ of power at $6000 \mathrm{rpm}$. When the fan was removed, the noise level fell from $150 \mathrm{~dB}$ to about $85 \mathrm{~dB}$, indicating the severity of the losses. These results did not support air cooling.

Reduction in No-load Spin Losses from Demagnetization and Fan Removal

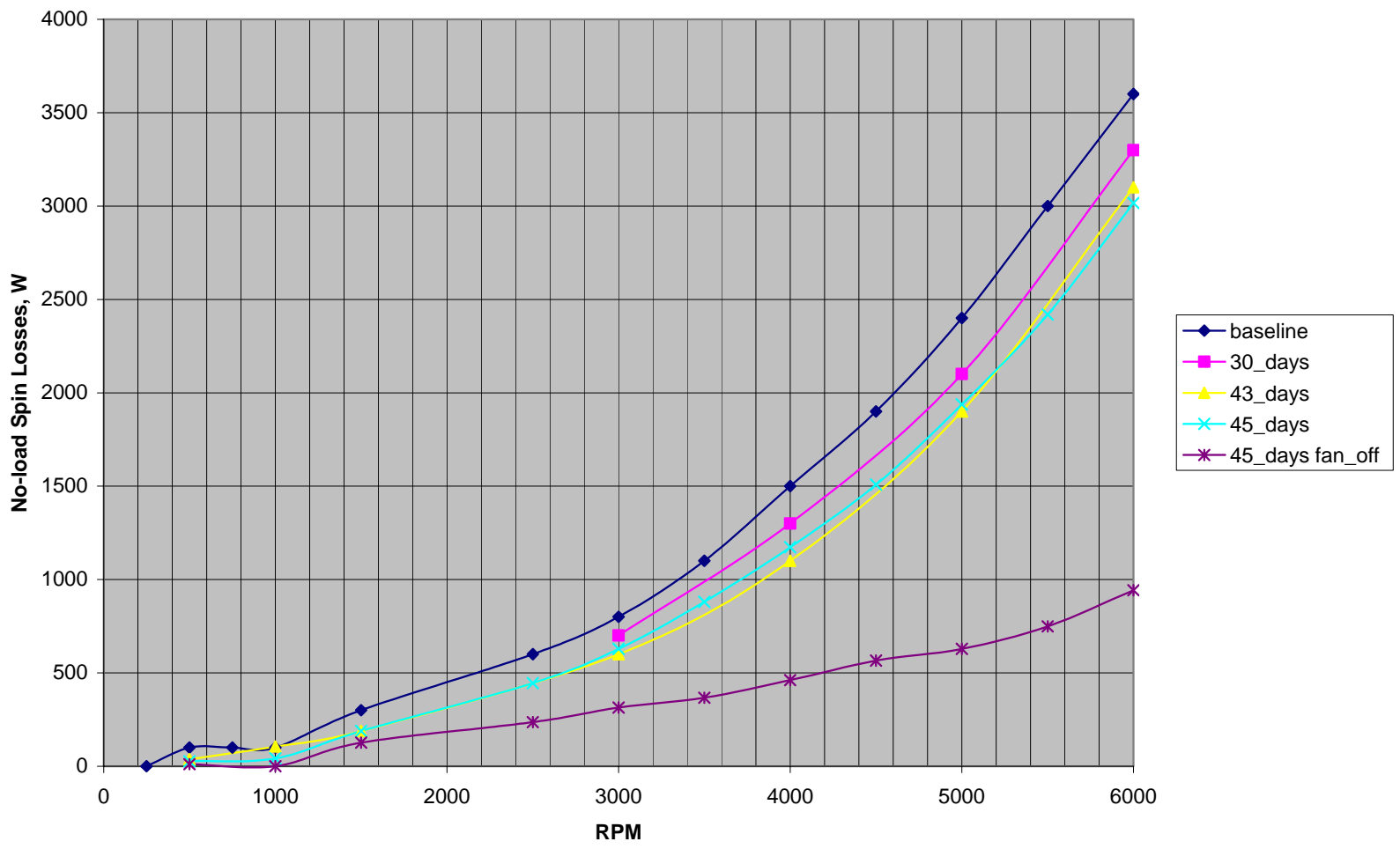

Fig. 5. Fan load penalty and change in no-load spin losses related to demagnetization during testing.

\subsection{DMIC MINIMIZES CURRENT USED BY MOTOR}

At any power level, the SCRs, which are the heart of the DMIC, enable maximum watts per rms amp control during constant power operation by minimizing rms current [3]. This feature is not possible with a voltage source inverter (VSI) driven motor, which has no SCRs, with a fixed inductance. In addition, losses can be substantially reduced using DMIC operation of PMSMs whose inductance is sufficiently large for VSI control (no SCRs) to achieve infinite CPSR. This current minimization was determined in addressing the question whether, assuming that the supply voltage can deliver the desired useful power and neglects the resistance, there is a value of inductive reactance, $X=\mathrm{n}_{\mathrm{b}} \mathrm{L}$, that minimizes the current. The answer is yes and the equation for that reactance is

$$
\mathrm{X}_{\min \mathrm{I}}=\mathrm{n} \Omega_{\mathrm{b}} \mathrm{L}=\frac{3 \mathrm{~V}_{\max }}{\mathrm{P}} \sqrt{\mathrm{n}^{2} \mathrm{E}_{\mathrm{b}}^{2}-\mathrm{V}_{\max }^{2}}
$$


which may be solved for the inductance needed at electrical frequency $\mathrm{n} \Omega_{\mathrm{b}}$. P is the developed power, $\mathrm{V}_{\max }$ is the supply voltage, $\mathrm{n}$ is the relative mechanical speed, $\mathrm{E}_{\mathrm{b}}$ is the back-emf, and $\mathrm{n} \Omega_{\mathrm{b}}$ is the electrical $\mathrm{rad} / \mathrm{s}$. With this optimal value of thyristor reactance, the minimum rms motor current is

$$
I_{\min }=\frac{P}{3 V_{\max }}=\frac{P}{3 \sqrt{E_{b}^{2}+\left(X_{b} I_{r}\right)^{2}}} .
$$

Equation (2) is independent of speed and directly proportional to developed power. If one substitutes the motor inductance for infinite CPSR, which is

$$
\underset{\mathrm{CPA} \rightarrow \infty}{\mathrm{CPA}-\mathrm{PMSM}}=\frac{\mathrm{E}_{\mathrm{b}}}{\Omega_{\mathrm{b}} \mathrm{I}_{\mathrm{r}}}
$$

for $X_{b}$ in Eq. (2) along with the relation for a PMSM, $P_{r}=3 E_{b} I_{r}, E q$. (2) leads to the linear relation in $P$,

$$
\frac{I_{\min }}{I_{r}}=\frac{P}{\sqrt{2} P_{r}}
$$

It can also be shown that the motor current is in phase with the inverter voltage phasor, which means that the inverter operates at unity power factor.

Figure 6 is a comparison of the motor current under CPA control with the motor current under DMIC for a PMSM. The linear relation between current and power of Eq. (4) is plotted at the bottom. As shown in reference [3], the equation for rms motor current,

$$
\mathrm{I}_{\mathrm{rms}}=\frac{\sqrt{\mathrm{V}_{\max }^{2}-\mathrm{n} \cdot 2 \mathrm{~V}_{\max } \mathrm{E}_{\mathrm{b}} \cos \delta+\mathrm{n}^{2} \mathrm{E}_{\mathrm{b}}^{2}}}{\mathrm{nX}_{\mathrm{b}}}
$$

with the inductance from Eq. (3) and the equalities, $\mathrm{V}_{\max }=\mathrm{E}_{\mathrm{b}} \sqrt{2}, \mathrm{P}_{\max }=\mathrm{P}_{\mathrm{r}} \sqrt{2}, \sin \delta=\frac{\mathrm{P}}{\mathrm{P}_{\mathrm{r}} \sqrt{2}}$, and $\cos \delta=\sqrt{1-\sin ^{2} \delta}$, leads to the rms motor current,

$$
I=I_{r} \sqrt{\frac{n^{2}-2 n \sqrt{2-\left(\frac{P}{P_{r}}\right)^{2}}+2}{n^{2}}} .
$$

Figure 6 is a plot of $\mathrm{I} / \mathrm{I}_{\mathrm{r}}$ versus $\mathrm{P} / \mathrm{P}_{\mathrm{r}}$ for $\mathrm{n}$ values of $2,4,6,8,20$, and $\infty$. The figure shows that when $\mathrm{L}=\mathrm{L}_{\infty}$, any developed power up to the rated power can be achieved without exceeding the rms current rating of the motor. The flatness of the CPA curves indicates that the copper losses in the motor are virtually independent of the developed power. Efficiency may be poor when operating conditions require a developed power less than the rated power. The DMIC's reduction in copper losses can be applied to compensate for the increased losses in the SCRs; and when there is a net reduction in total inverter plus 
motor losses, that reduction can be applied over the operating life of the drive toward the added initial cost of the SCRs.

This type of analysis provides a relationship showing the current that may be saved at various operating speeds by using the DMIC instead of CPA or vector control, so that operational cost/benefit estimates may be made based on the application's expected duty cycle. In any life-cycle cost study, this information, which is not the first or initial cost, must be included because it can provide significant benefits to the customer.

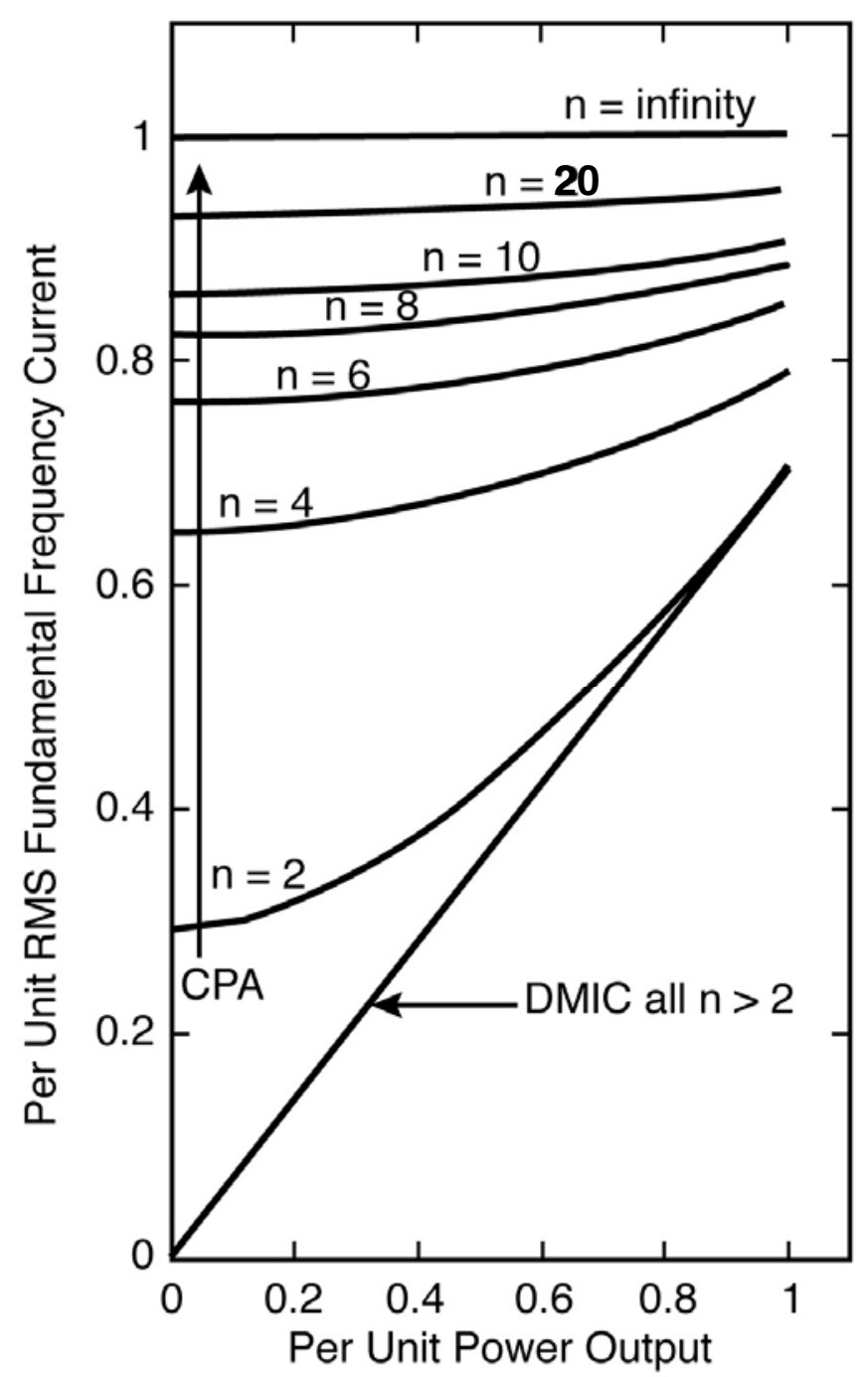

Fig. 6. Constant power operation of a PMSM comparing CPA control with DMIC.

\subsection{ONSET OF YIELD DETERMINES MAXIMUM OPERATING SPEED}

Electric motors are designed to provide specific torque and useful power; however, a crucial question for any motor design is its maximum speed capability. Estimates may be made using force balance equations and elastic equations for rotational systems axisymmetric about an axis. These techniques, which may be matched to estimated circumferential stress and radial interference requirements (radial stress), provide only a rough idea of the speed capabilities of a particular configuration. In each design, the magnets 
generate an equiangular load that adds bending stresses to the tensile stresses; consequently, a finite element code is needed to determine a more representative picture of the stresses and deformation of the components of the motor. The Power Electronics and Electric Machinery Research Center (PEEMRC) at ORNL has used ALGOR stress analysis to examine the mechanical capabilities of the interior PM (IPM) motors.

Since the rotor material is ductile, if failure is generated in the rotor, an excellent way to estimate its maximum rotational speed is to adjust that speed so that the von Mises stress equals the rotor's yield strength. Yield strength is obtained from a uniaxial tensile test at the onset of plastic flow. One is tempted to use the ultimate strength; but this is not wise because plastic flow allows the components to move, which may create imbalances that will lead to failure.

For ductile materials, experience has shown that the von Mises stress provides a dependable and nonconservative estimate of failure. This approach assumes that yield, which is the onset of plastic deformation, is caused by a critical shear stress on an octahedral plane. The normal to the octahedral planes have equal direction cosines with the three axes. The expression for octahedral shear stress is

$$
\tau_{\mathrm{oct}}=\frac{1}{3} \sqrt{\left(\sigma_{\mathrm{x}}-\sigma_{\mathrm{y}}\right)^{2}+\left(\sigma_{\mathrm{y}}-\sigma_{\mathrm{z}}\right)^{2}+\left(\sigma_{\mathrm{z}}-\sigma_{\mathrm{x}}\right)^{2}+6\left(\tau_{\mathrm{xy}}^{2}+\tau_{\mathrm{yz}}^{2}+\tau_{\mathrm{zx}}^{2}\right)} .
$$

In the uniaxial test, all components of stress except for $\sigma_{\mathrm{x}}$ are zero. The value of the critical octahedral shear stress may be obtained from the uniaxial test data by substituting $\sigma_{\mathrm{x}}=\sigma_{\text {yield }}$ in Eq. (7). The result is

$$
\tau_{\text {oct }}=\frac{\sqrt{2}}{3} \sigma_{\text {yield }}
$$

When more complex loading occurs for which terms in Eq. (7) are not zero, it may be set equal to Eq. (8). The result is that

$$
\sigma_{\text {yield }}=\sqrt{\frac{\left(\sigma_{x}-\sigma_{y}\right)^{2}+\left(\sigma_{y}-\sigma_{z}\right)^{2}+\left(\sigma_{z}-\sigma_{x}\right)^{2}+6\left(\tau_{x y}^{2}+\tau_{y z}^{2}+\tau_{z x}^{2}\right)}{2}},
$$

where the term on the right of Eq. (8) is known as the von Mises stress or the effective stress.

Different failure modes may require different criteria to determine maximum operating speed. For example, if the failure mode is fracture of the magnets, which are brittle materials, the criteria for operation will necessitate a Weibull distribution of the magnets' transverse fracture strength. From this distribution, a maximum stress may be determined to achieve the required probability of fracture.

The IPM machines are progressing through an evolution shown in Fig. 7 that significantly increases their speed capabilities. Three types of machines, two of which are already in the market, were examined using the ALGOR finite element program. The two include the Toyota Prius THS motor (2003) and the Toyota Prius THSII motor (2004). A third shown in Fig. 8 has been researched by Honda and comprises surface-mounted magnets that are self-supported by the rotor steel and flush with the steel that secures them. A fourth is being investigated by ORNL as a modification of the THSII to deliver increased torque and power using the principles of the high-strength undiffused brushless (HSUB) motor. 

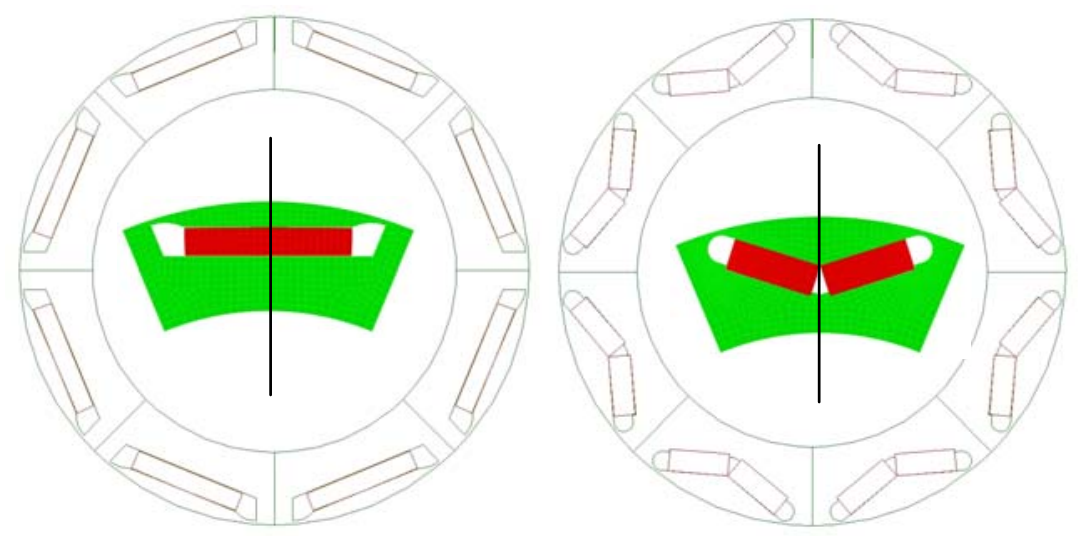

Fig. 7. Evolving IPM rotor configurations (THS left, THSII right).

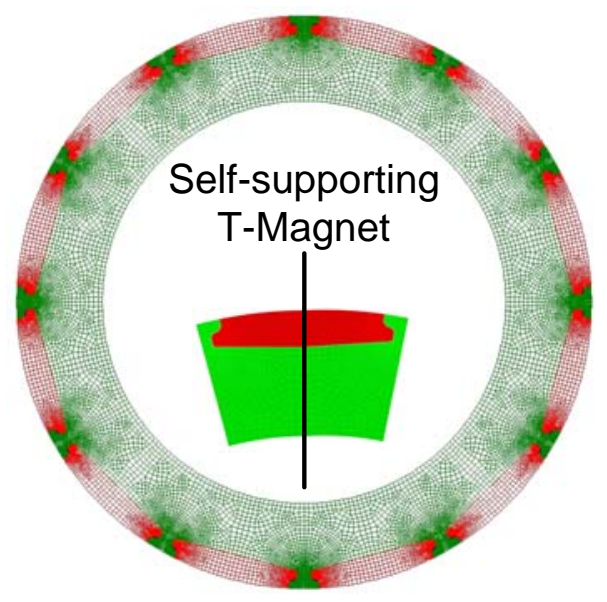

Fig. 8. Rotor supported magnet configuration.

IPMs move within their cocoon of M19 steel during operation. To observe how they are loading the M19 with the finite element code, it is necessary to use gap elements, which come into play only when their initial dimension is reduced. Such a reduction indicates that the materials are trying to overlap. Although this is mathematically possible, it is realistically unacceptable. To prevent this from happening, stiffnesses normal to the surfaces are incorporated as part of the stiffness matrix. Since this is a nonlinear calculation, the model in the configuration must be elastically stable when the first load increment is applied. This stability is provided by using a spring element so soft that it will not significantly impact the final solution. After each load increment, the gap elements are checked to see which ones have diminished; and one by one, those that have diminished are added to the stiffness matrix. The load along each active gap element is calculated. The load for inactive gap elements is zero.

In each IPM model, the load of the magnets and all of the outboard material must be supported through a connection by the remaining spoke-like portions of the rotor. This connection is called the bridge. The significant mechanical contribution of the Toyota Prius THS motor is the use of two 1-mm-thick peripheral connection bridges of M19 Si steel between the loaded region and the supporting spokes. This magnet loading is shown in Fig. 9, in which it appears that the rotor interface between the magnet and periphery bends, allowing the magnet load to be applied only at its outer edge. Because of symmetry, the total magnet load appears to be $240 \mathrm{lb}$. Figure 10 shows the onset of plastic deformation in the inner surface of the bridge near the spoke, indicating that the maximum operating speed is $5686 \mathrm{rpm}$. 


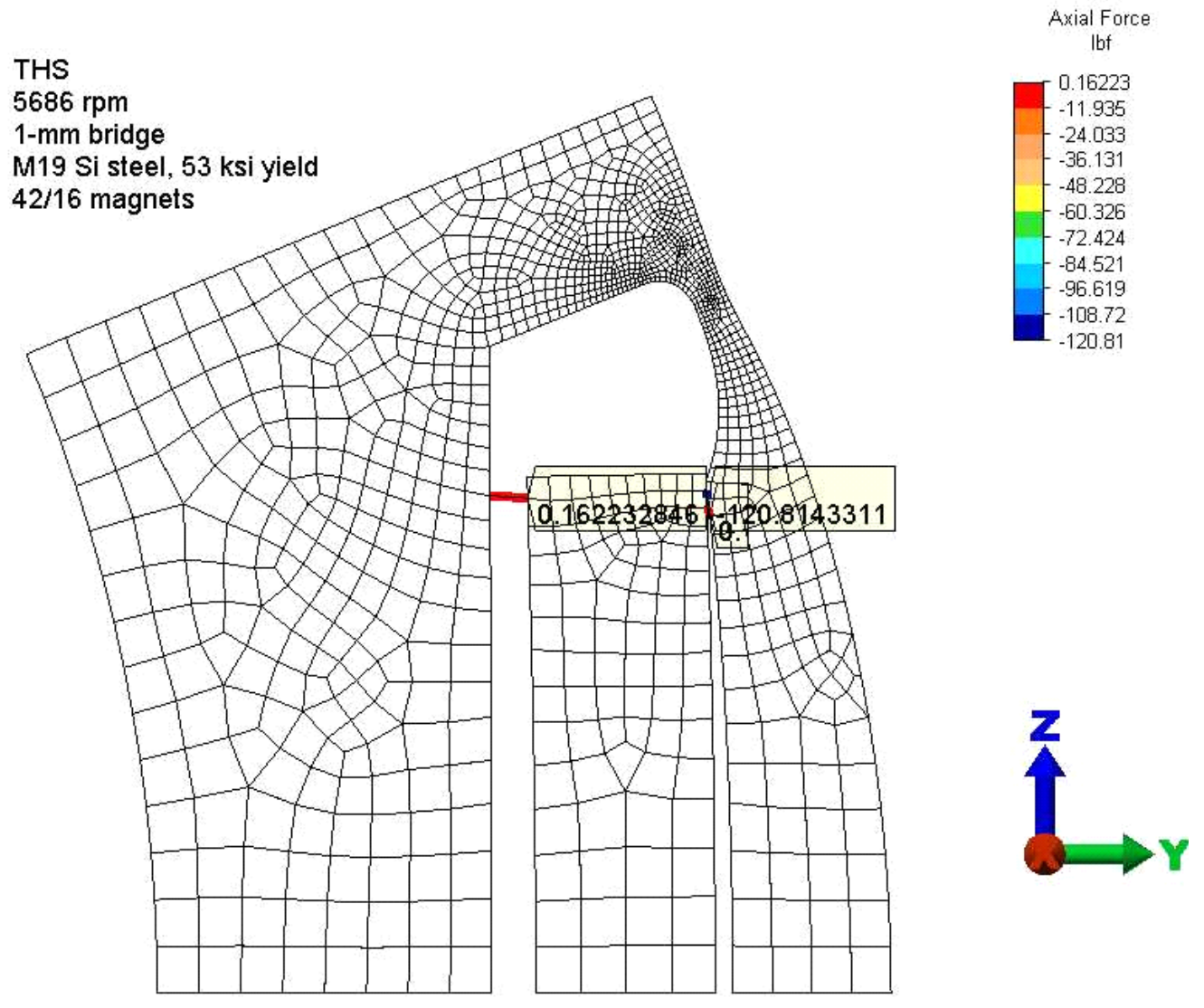

Fig. 9. Magnet loading in the THS design.

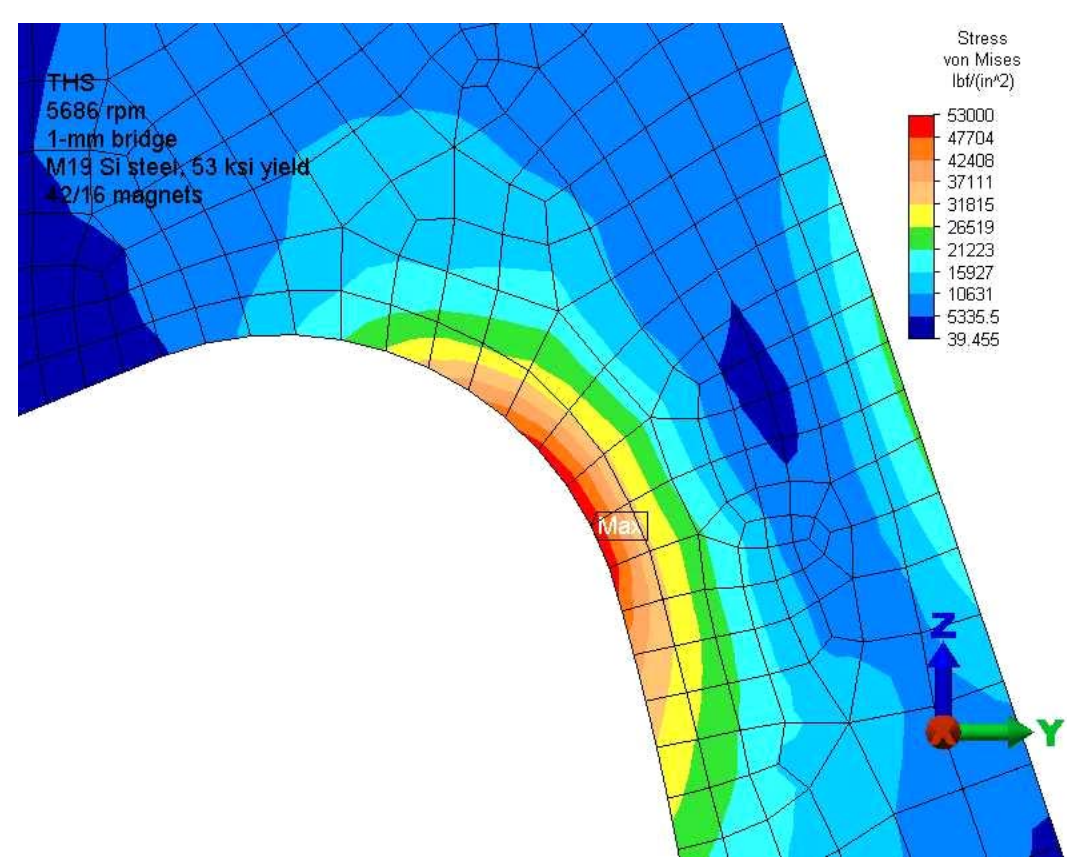

Fig. 10. Onset of plastic deformation in the THS rotor. 
The impressive additional mechanical contribution of the THS 2 motor is the addition of a ledge on the spoke side to carry a large part of the magnet load and relieve the load on the bridge. Figure 11 shows that the magnet load supported by the ledge on the spoke side of the cocoon is $102 \mathrm{lb}$. The result of this load redistribution is that the maximum operating speed before the onset of plastic deformation is increased by $10 \%$ to $6231 \mathrm{rpm}$. Figure 12 shows that the stresses in the bridge at the onset of plastic deformation are similar those of the THS motor. Results of a parametric study of the speed capability as a function of bridge thickness are shown in Fig. 13.

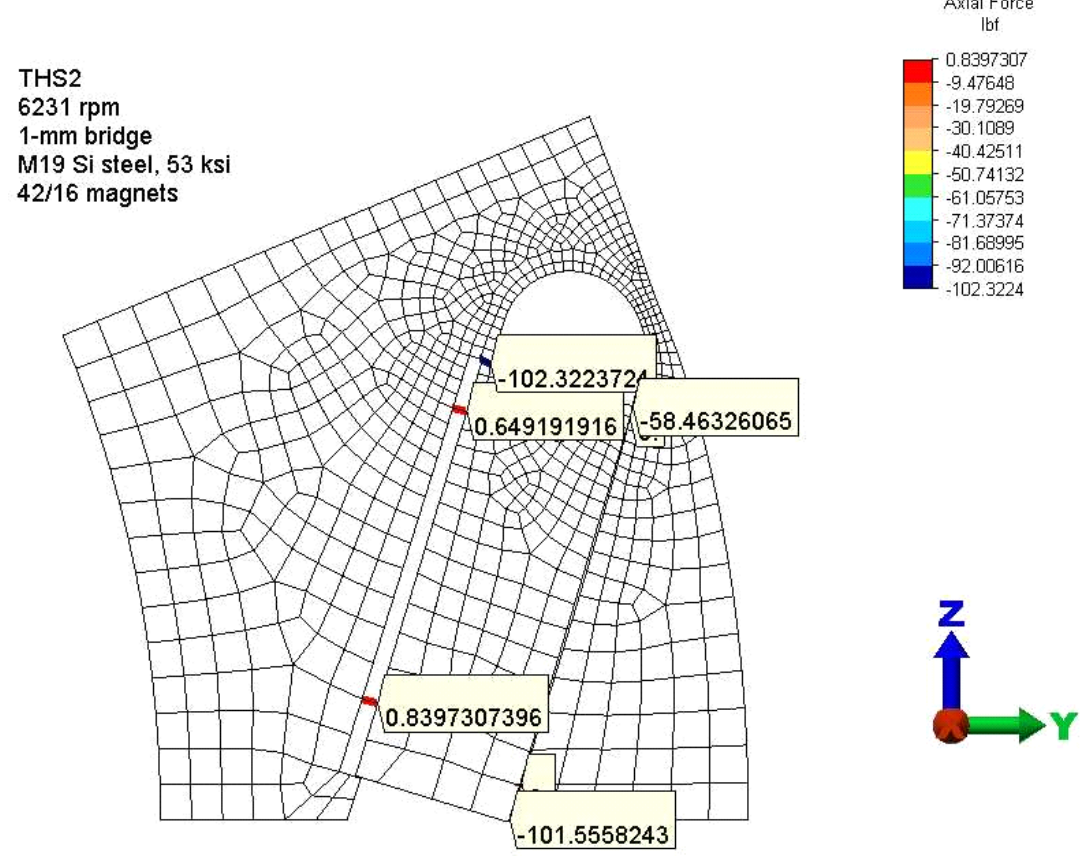

Fig. 11. Magnet load in the THSII rotor.

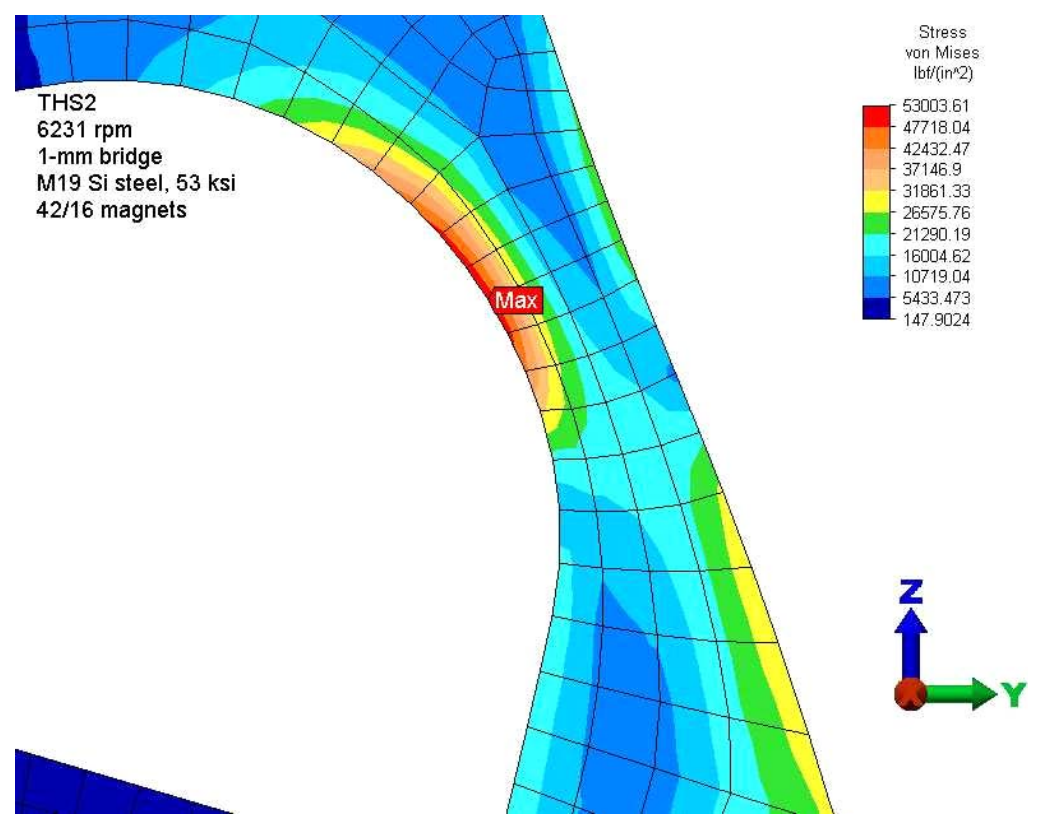

Fig. 12. Beginning of plastic deformation in the THSII rotor. 


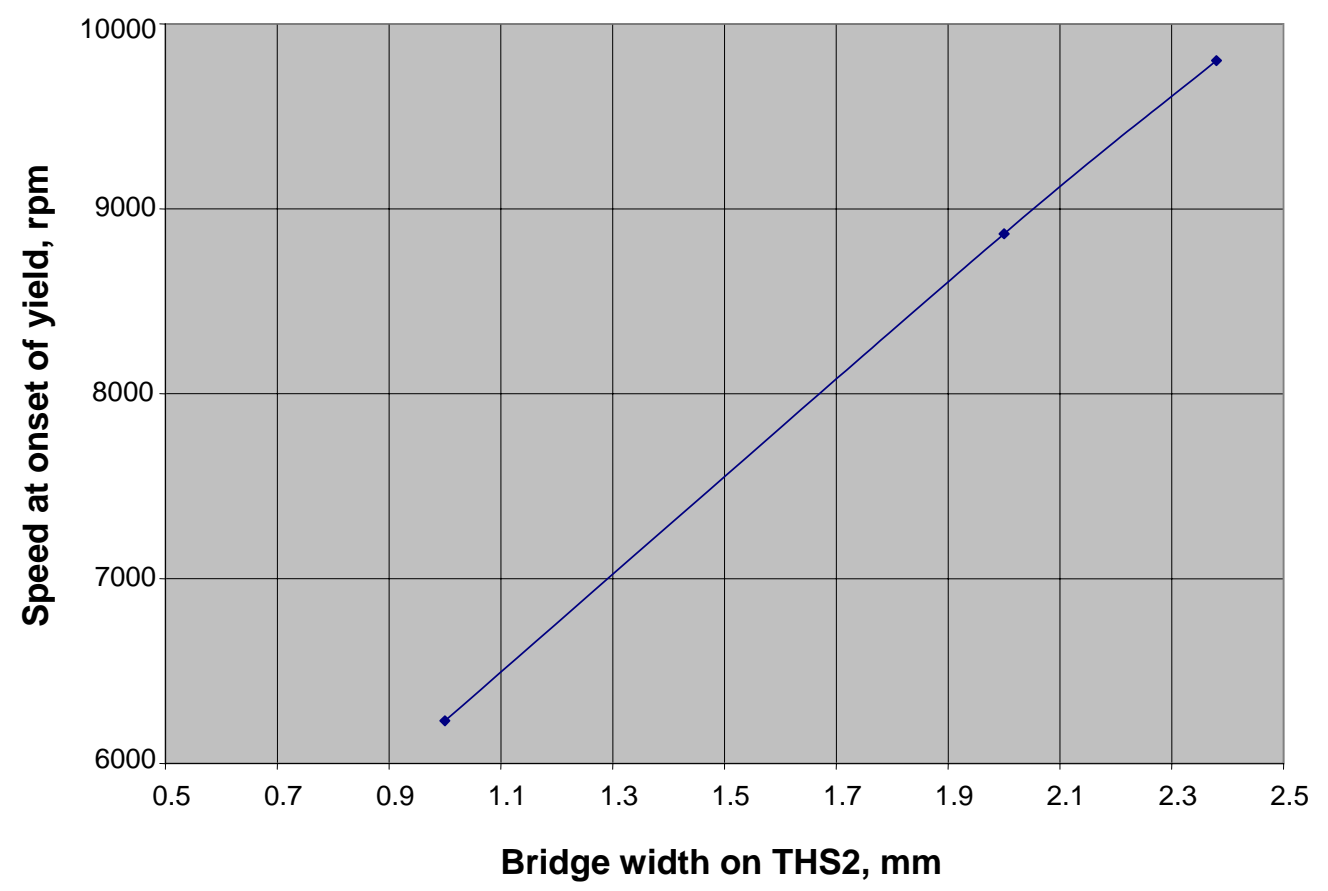

Fig. 13. THSII speed dependence on bridge thickness.

A third type of rotor being examined employs rotor-supported magnets. It has the features of a rotor with surface mounted magnets separated by rotor steel, which uses hooks or tabs to support the magnets. Reluctance now contributes to the torque. The magnets exert a compressive load on the tabs, as shown by the loads on the gap elements in Fig. 14. The effective stresses are shown in Fig. 15. If the von Mises criterion is applied to this compressive load, then the failure speed is $9237 \mathrm{rpm}$.

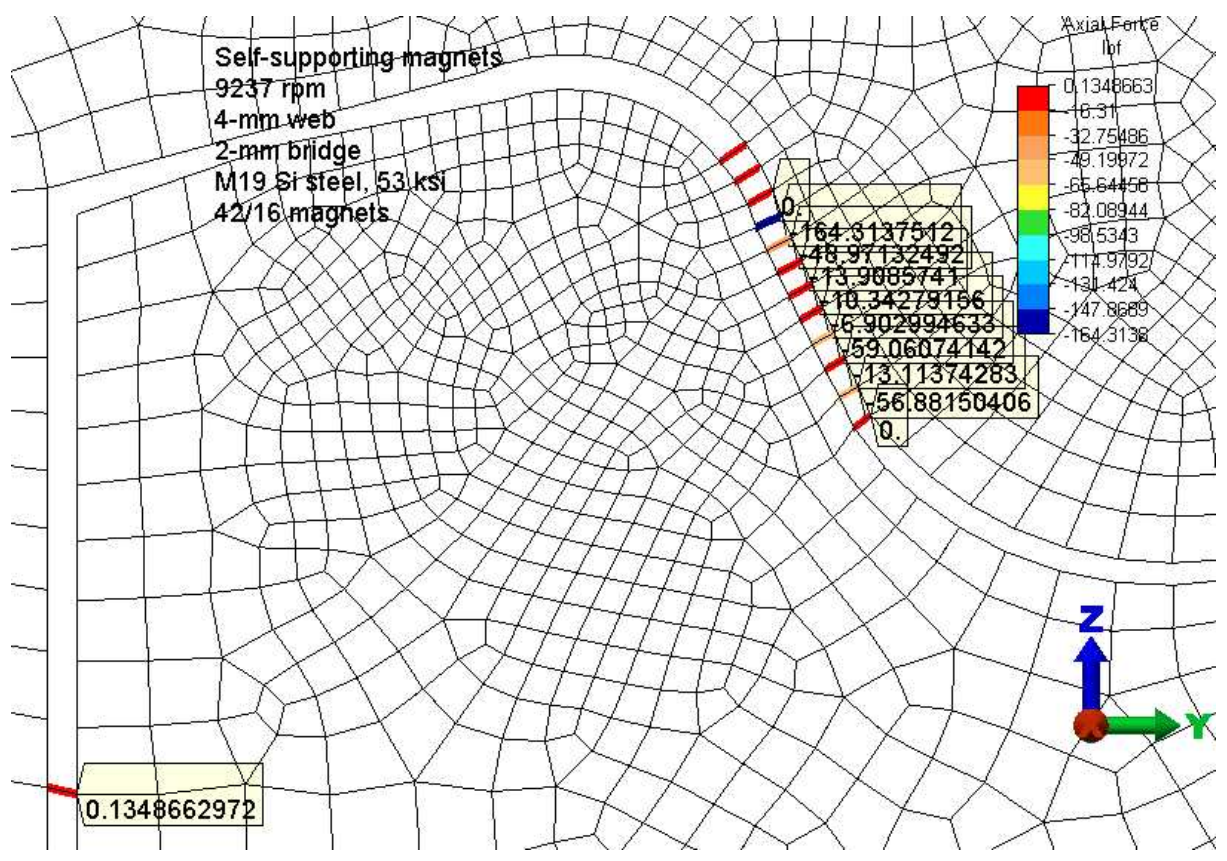

Fig. 14. Magnet load on tab of rotor supported magnet configuration. 


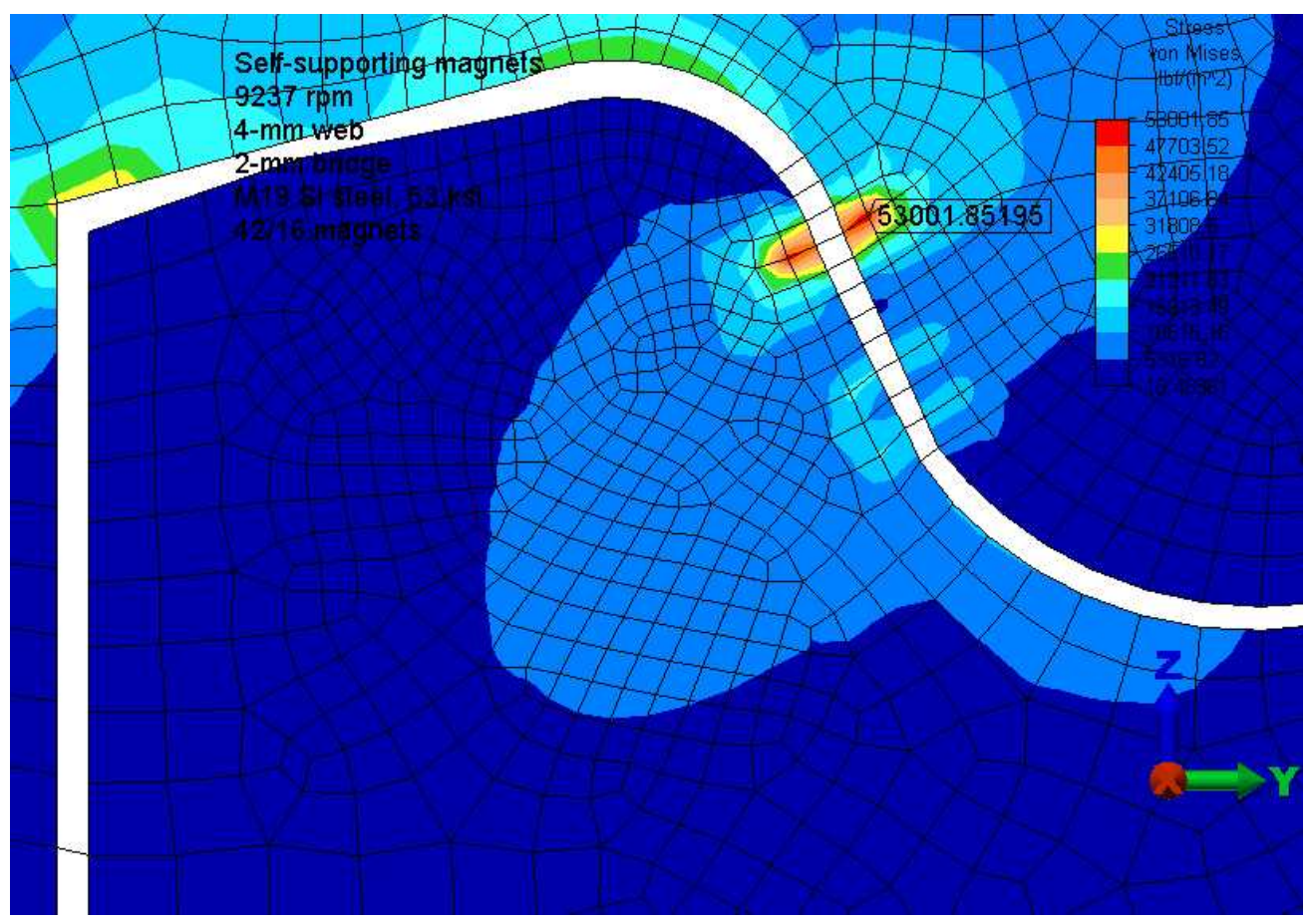

Fig. 15. Onset of plastic compression in rotor that supports its own magnets.

The fourth type of rotor proposed by ORNL is the modified THSII rotor, which uses the ledge of the THSII with the two magnets rotated into a radial orientation, adds an inner magnet to connect their inner corners, and employs a post or pile to provide additional support between each end of the inner magnet and the large region loaded by the magnets. Initial examination using the finite element approach indicated that $9715 \mathrm{rpm}$ is the maximum operating speed prior to the onset of plastic deformation of the high-strength undiffused (HSU) configuration using 1.2- $\mathrm{mm}$ bridges and 1.2-mm piles. The magnet loading on the ledge is shown in Fig. 16, and the onset of plastic deformation at the inner pile is shown in Fig. 17. 


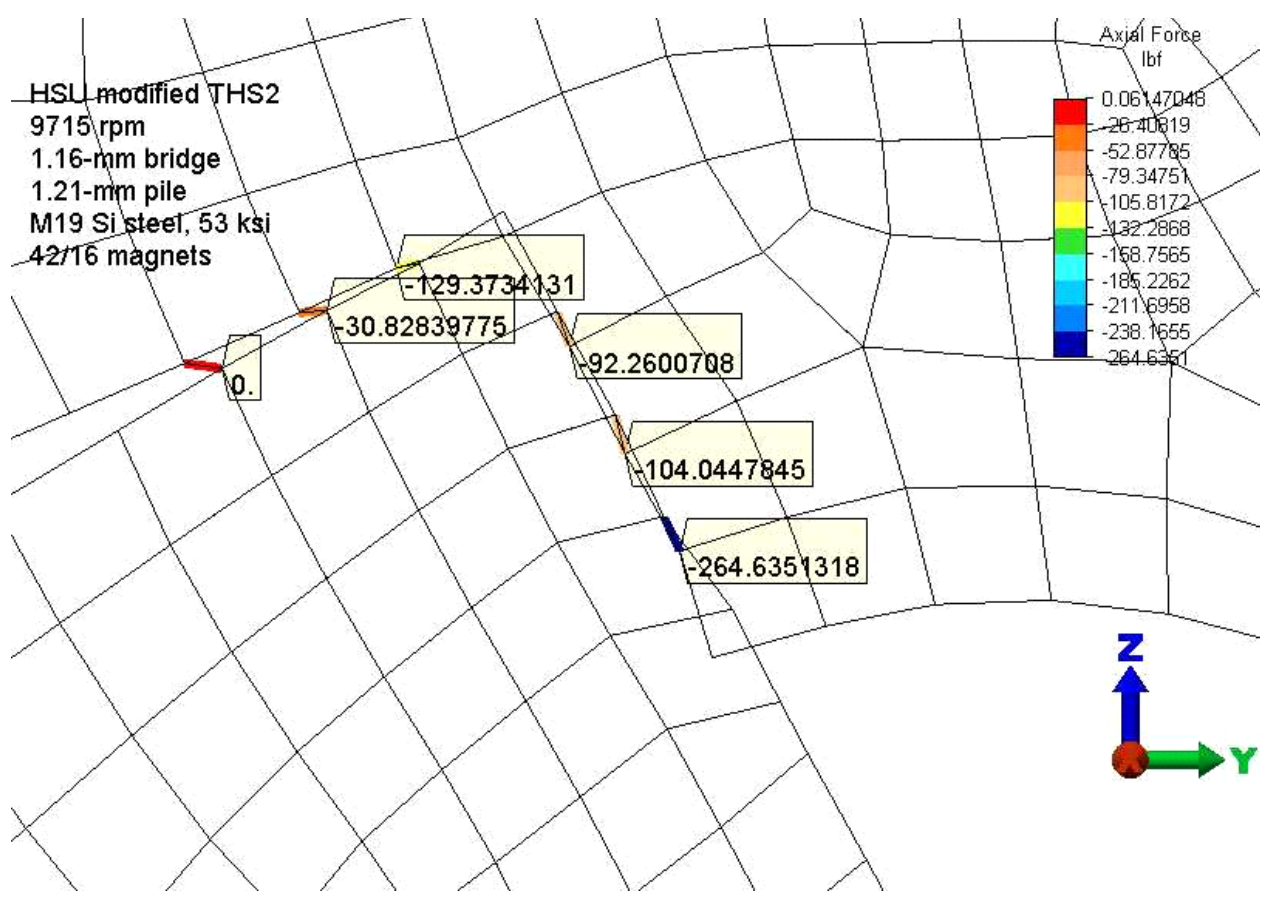

Fig. 16. Magnet load on the ledge of the modified THSII.
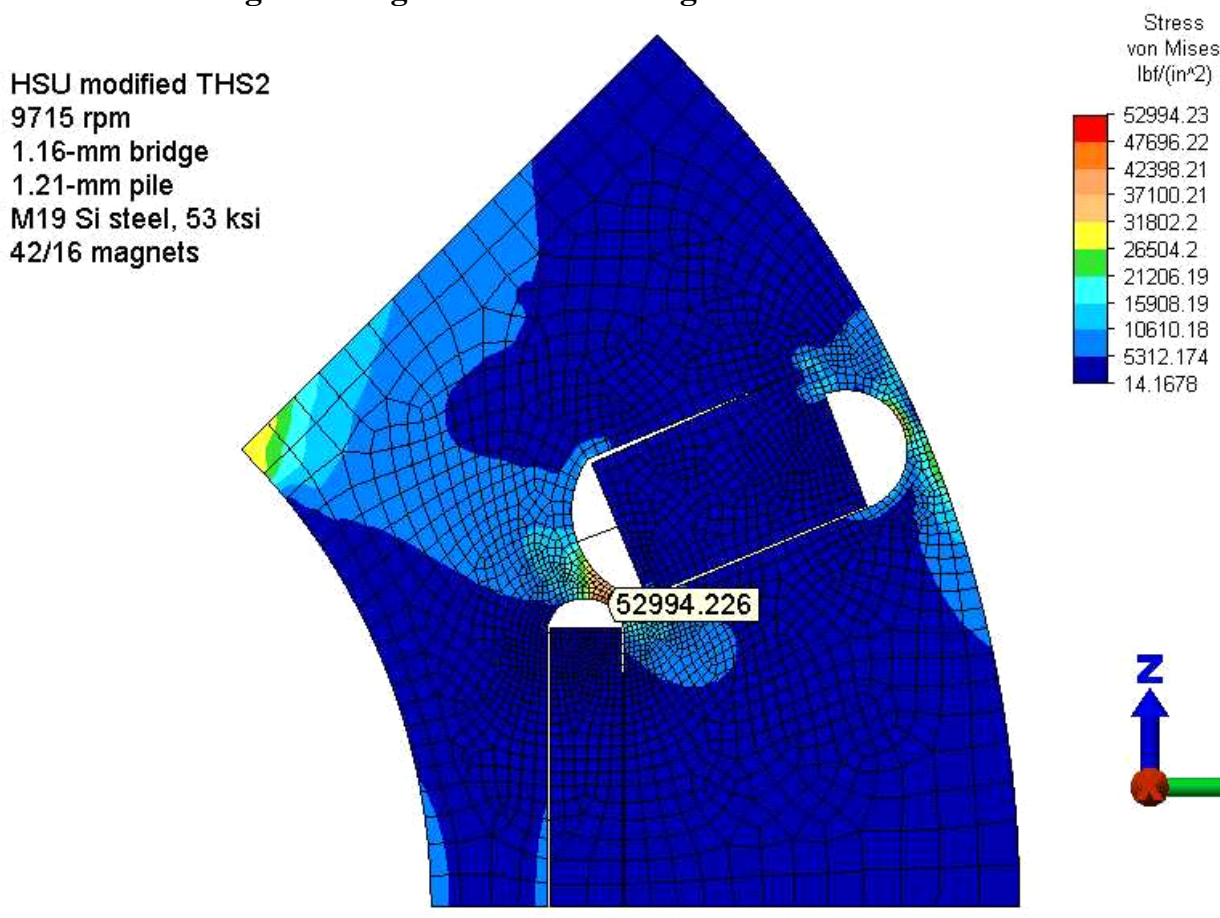

Fig. 17. Onset of plastic deformation in the modified THSII. 


\section{CONCLUSIONS}

Axial gap motors can be constructed for high-speed operation at up to $6600 \mathrm{rpm}$ using the radial interference design concept to compensate for speed-dependent mechanical deformations and for differential thermal expansion. However, when they are driven with a trapezoidal back-emf, there are significant temperature excursions that threaten the magnets. Similar experience in the commercial sector with radial gap PM motors suggests that the use of sinusoidal back-emfs can reduce but not eliminate thermal excursions. It appears that the excursions occur as harmonics induce eddy currents in the rotor. A methodology is available to calculate the no-load eddy current spin losses generated by the magnet passing the slots between the teeth, and the operational eddy current spin losses generated by harmonic currents.

The DMIC inverter is capable of driving an 18-pole PM motor to $6000 \mathrm{rpm}$ where the electrical frequency is $900 \mathrm{~Hz}$. The cheaper converter-grade SCRs are capable of natural commutation at this frequency; consequently, their incremental cost impact on an inverter is more attractive to those who are considering using DMIC.

Both DMIC and CPA control were able to demonstrate legitimate record CPSRs. The excellent behavior under CPA control was a surprise because, using the derated parameters of the motor, we determined that the phase inductance should be greater than $190 \mathrm{uH}$ for operation under CPA control at a CPSR of 12. The measured phase inductance of this motor was $158 \mathrm{uH}$.

DMIC defines the minimum current necessary to deliver any power up to rated power at any relative speed over $2 \mathrm{mph}$. This is significant because it quantifies the savings in current that can be attained for applications that operate much of their lifetime at high speeds. The PEEMRC is collaborating with a U.S. company to investigate a specific application.

Small 1-mm peripheral bridges and support posts have enabled IPM rotors to operate at very high speeds. FEA is useful to quantify these speeds and to show where failure, defined as the onset of plastic deformation, occurs. Commercial models have exhibited splendid capabilities. Some new concepts being explored by ORNL show improved capabilities. 


\section{REFERENCES}

1. R. L. Russell et al., "Eddy Currents and Wall Losses in Screened-rotor Induction Motors," Institute of Electrical Engineers, Paper No. 2525U, April 1958.

2. A. M. EL-Refaie, D. W. Novotny, and T. M. Jahns, "A Simple Model for Flux Weakening in Surface PM Synchronous Machines Using Back-to-Back Thyristors," IEEE Power Electronics Letters, 2, (2), June 2004.

3. J. S. Lawler et al., "Minimum Current Magnitude Control of Surface PM Synchronous Machines," in preparation (responding to Ref. 2).

4. Satoh et al., "Development of Traction Motor for Fuel Cell Vehicle," Paper No. 2004-01-0567, presented at the 2004 SAE World Congress, Detroit, March 8-11, 2004. 


\section{INTERNAL DISTRIBUTION}
1. D. J. Adams
2. C. W. Ayers
3. J. M. Bailey
4. S. Das
5. E. C. Fox
6. J. S. Hsu

\author{
7. J. S. Lawler \\ 8. L. D. Marlino \\ 9. J. W. McKeever \\ 10. L. E. Seiber \\ 11. G. J. Su \\ 12-13. ORNL Laboratory Records
}

\section{EXTERNAL DISTRIBUTION}

14. S. A. Rogers, U.S. Department of Energy, EE-2G/Forrestal Building, 1000 Independence Avenue, S.W., Washington, D.C. 208585.

15. E. J. Wall, U.S. Department of Energy, EE-2G/Forrestal Building, 1000 Independence Avenue, S.W., Washington, D.C. 208585. 